\title{
Smart Mobility: The Cases of Hong Kong and The Netherlands
}

\author{
Luisa Maria Calabrese \\ Department od Urbanism, Faculty of Architecture, Delft University of Technology, Delft, The Netherlands
}

\begin{abstract}
The purpose of this paper is to address the need for cross-disciplinary, collaborative international research that supports implementation of a 'smart mobility' for sustainable urban transportation. Progress toward a positive, integrated, and sustainable future for urban transportation will require more than technology. According to Susan Zielinski (2006) there are three frontiers of thinking and practice for Smart mobility, namely: complexity, accessibility and new business models (1). To our view, in addition to Zielinski's frontiers of thinking there are at least three other fundamental aspects to be considered in order to create a framework for Smart mobility, namely: matching Business and Technology; integrating Spatial Planning with Transportation Planning; promoting a cultural change. Besides, innovations such as Smart Cards, On-Line Traveller Information, Car-Sharing, bundled mobility packages and snappy marketing techniques are coming together and changing the way investors and users think about urban transportation.
\end{abstract}

Keywords : Smart mobility, Spatial planning, Cultural heritage

1. Introduction: the unimaginable is here When Le Corbusier published his manifesto for a futurist city in the New York Times on January 3, 1932 it is unlikely that the idea of an "IPad" would have entered his mind, let alone mesh networking, GIS, or "Googling” or 'Facebooking', He wouldn't have conceived of the connectivity that a mere half-century later has brought these elements together, transformed the world, and evolved into one of the fastest growing, most pervasive global industries. However it is no understatement to say that Le Corbusier's plan for the utopian Contemporary City forever altered the urban fabric of twentieth-century cities. Le Corbusier created his plan for the Contemporary City in 1922, and published its finished version in The City of Tomorrow and its Planning in 1929, just as modernist architecture was gaining a foothold internationally. Upon trying his hand in urban planning, Corbusier incorporated modernist principles like efficiency, geometry, and mass production into his work. In fact, the Contemporary City wholly revolves around
Corbusier's forward-looking axiom, "a city made for speed is made for success”. Corbusier emphasized these same concepts, which many critics associate with modernism as a whole, with his ideas for the streets and transportation of the Contemporary City. He proposed revolutionizing the typical urban street plan: moving from many narrow, crooked streets that are "the old bare ground which has been paved over" toward a few large, efficient expressways that cut a broad swath through the city (Corbusier 325). Declaring, "cross-roads are any enemy to traffic" because of stoplights and the like, Corbusier proposed that the number of streets should be reduced by two thirds. In a typically orderly Corbusian fashion, the Contemporary City had three separate roadway systems. Heavy and unsightly industrial-type traffic was buried underground and away from sight; travellers within the city were permitted to drive about it as usual; and large expressways were built ringing the city. By imposing a strict grid system on the city and segregating different types of vehicles onto completely separated roadways, the streets of Corbusier's city optimize the flow of traffic. Even though Corbusier wrote Principles of Town Planning in the 1920s, he astutely predicted the total reliance on the car mid-century, and designed the Contemporary City completely around it. By creating only large expressways slicing through giant, pristine parks, he effectively did away with pedestrian pathways and walkable downtowns. Also, he removed trains in favour of an intricate bus system, as he regarded all transportation running on fixed tracks as inefficient.

This arrangement, however, ends up strictly economically segregating the Contemporary Citizens, leading to long commutes for those in service jobs and a distinct lack of vibrancy in the city.

Le Corbusier's ideas about mobility transformed radically not only the form and function of the city, but especially the way contemporary urban planning works. Today, we are on the edge of a comparable transformation for cities called 'Smart mobility' (Zielinski, 2006). Accelerated by the emergence of new fuel and vehicle technologies; new information 
technologies; flexible and differentiated transportation modes, services, and products; innovative land use and urban design; and new business models, collaborative partnerships are being initiated in a variety of ways to address the growing challenges of urban transportation and to provide a basis for a vital Smart mobility industry (MTE and ICF, 2002). Nowadays urban mobility should make possible the economic development of towns and cities, the quality of life of their inhabitants and the protection of their present and future environment.

\section{Why 'Old Mobility' is not the answer}

The notion of "Smart mobility" offers a serious approach to tackle urgent global and local issues.

To appreciate fully what "Smart mobility" means, it is useful to see how it differs from "Old Mobility" (often defined as being stuck in traffic, waiting in the rain for a bus that may never come, or paying large amounts of taxpayer money for "improvements" that ultimately find us still late for work or waiting for that bus).

What we now call "old mobility" thinking and practice is in effect the dominant paradigm of 20th century visions and practices in urbanism. It is/was essentially oriented to the search for engineering, technological and infrastructural solutions for increasing speed and throughput capacity in specific links and at key points (including bottlenecks). The old mobility paradigm was one that has been characterized as "forecast (growth) and build". Old mobility solutions more often than not cost a lot of money, and created a broadly shared mind-set in which the main limit to providing for yet further capacity increases within the system was constrained only by funding limitations from public sources. The old system was and is essentially hierarchical and "expert oriented and controlled”. It is still dominant in many cities and parts of the world today. Since this entry is still in progress, here is an attempt to characterize the present arrangements and constraints that form it very broadly. By understanding these - if (a) true and (b) really a problem - we have a base for fine-tuning our proposed new solutions.

The heart of smart mobility policy by contrast is systemic complexity, diversity, participation, wide outreach and a wide array of partnerships and other forms of synergistic interaction and collaboration. It more often involves the orchestration of a large number of measures and policies, many of which often very small in themselves, in order to provide a dispersed modern city encompassing many different types of people and mobility needs - as opposed to the "big solution" approaches often favoured in the past (whether major highway or road building or extensions, new Rapid transit (metros, subways or other expensive rail systems, massive central parking structures, and the like). The goal of the planners and authorities changes radically with this new paradigm, such that rather than "solving problems” with centrally planned and executed engineering and measurement; they start to get more involved in multi-level complex problemsolving, which brings them to such quite different kinds of approaches such as community outreach and orchestration of services and the participation of a much larger number of actors and players.

The Smart mobility addresses the issues on both the supply and demand sides. It thus combines Transportation Demand Management TDM strategies and measures for containing, channelling and limiting wasteful and encumbering private car traffic in cities, with coordinated support of a wide "bouquet" of alternative transportation arrangements. These include various forms of Human-powered transport, utility cycling, walking, public space improvement, electronic substitutes for travel (such as telework, telecommuting or e-work) and a variety of shared and public transport strategies, new and old, including HOV (High Occupancy Vehicles), carpooling, ride sharing, car rentals, taxicab and shared taxi.

\section{Smart Mobility versus Sustainable Transportation}

Smart mobility and Sustainable Transportation are closely related but not identical concepts. The term "Sustainable Transportation" had it origins in the mid-eighties and has developed over time and for the most part with particular emphasis on informing transport and environmental policy, with support from a number of university programs, NGOs and from some international and government organizations. By contrast the term Smart mobility takes the issues of sustainable transportation the other way around: by emphasizing the supply side - and specifically targets projects and programs, which demonstrate and achieve the basic principles behind sustainable transportation. According to the latest report on mobility issued by the European Union (2) in Europe, over 60\% of the population lives in urban areas. Just less than $85 \%$ of the EU's gross domestic product is created in urban areas. Towns and cities are the drivers of the European economy. They attract 
investment and jobs. They are essential to the smooth functioning of the economy. Urban areas now constitute the living environment of the vast majority of the population, and it is imperative that the quality of life in these areas should be as high as possible. That is why we must now pool our thoughts and consider the question of urban mobility. European towns and cities are all different, but they face similar challenges and are trying to find common solutions. Throughout Europe, increased traffic in town and city centres has resulted in chronic congestion, with the many adverse consequences that this entails in terms of delays and pollution. Every year nearly 100 billion Euros, or $1 \%$ of the EU's GDP, are lost to the European economy as a result of this phenomenon. Air and noise pollution is getting worse year by year. Urban traffic is responsible for $40 \%$ of $\mathrm{CO} 2$ emissions and $70 \%$ of emissions of other pollutants arising from road transport. The number of road traffic accidents in towns and cities is also growing each year: one in three fatal accidents now happen in urban areas and it is the most vulnerable people, namely pedestrians and cyclists, who are the main victims.

While it is true to say that these problems occur on a local level, their impact is felt on a continental scale: climate change/global warming, increased health problems, bottlenecks in the logistics chain, etc.

Local authorities cannot face all these issues on their own; there is a need for cooperation and coordination at national and international level. The vital issue of urban mobility needs to be addressed as part of a collective effort at all levels: local, regional, national and international.

Smart mobility is not merely reliant on individuals and their individual behaviour and is, above all, the responsibility of local politicians and citizens. In order to avoid the social disparities linked to mobility access (i.e. those households not having an alternative to a car or having limited resources), it is important to consider sustainable development not as straightforward individual accountability, but rather as a way of re-examining how our urban space and our way of urban life are organised.

It is often said that the development of public transport can contribute to bringing a permanent solution to this problem, yet, as Olivier PaulDubois-Taine demonstrates, this is far from being optimal. Increasing the number of buses and school bus routes would undeniably cause a significant increase in $\mathrm{CO} 2$ emissions per inhabitant, yet without providing genuine improvements in terms of people's mobility.
We need, therefore, to examine technology, territory and social fabric, since mobility must not simply be conceived as the capacity to cover a certain distance in a given time; it is a way of travelling to the various facilities that characterise everyday urban life: work, culture, social life, shopping, etc. In other words, mobility questions our territorial organisation, which must be considered in terms of access to services. To do so, it is possible to act at different levels, among which the development of more cost- and fuel-efficient vehicles, the implementation of mobility services allowing the rational use of these new vehicles (carpooling, car sharing...) and the development of remote telecommunications (homeworking, home deliver) are the most important.

In the same way, and in the longer term, we need to take a fresh look at accessibility to services depending on the territories concerned and to find new adjustment limits so as to promote mobility as much as possible. Concentrating on replacing and limiting vehicles is not the only solution. We need to rethink the whole system. Accessibility to housing and territories is a key question and the location of everyday services must be organised, reconsidered and planned. For this, it seems appropriate to refocus our activities on residential zones and service hubs, and to limit and carefully consider the daily use of vehicles that are less heavy, consume less and pollute less than is the currently the case. The car must no longer be the central access point to urban and metropolitan mobility. Social and technological transformation must be considered as a system combining the different aspects already referred to. This means that the breakaway represented by new means of mobility cannot happen without the assistance of local authorities and intensive communication in order to make local players and citizens responsible. Although the development of electric vehicles and new services may lead to the appearance of new operators with solutions for the future, it is important for governments to contribute towards the development of this trend. In any case, they will have to come to terms with it rather soon.

\section{Creating a framework for Smart Mobility}

The evolution of Smart mobility is inspired by emerging innovations and propelled by pressing needs, not the least of which is rapid urbanization. Although a few cities are shrinking, especially in the developed world, by 2030 more than 60 percent of the world population and more than 80 percent of the 
North American population will live in urban regions (UN, 1996). With increasing motorization, traffic volume and congestion are already resulting in lost productivity and competitiveness, as well as health and other costs related to smog, poor air quality, traffic accidents, noise, and, more recently, climate change (WBCSD, 2001). At the same time, sprawling, car-based, urban development patterns can mean either isolation or chauffeur dependence for rapidly aging populations, as well as for children, youths, and the disabled (AARP, 2005; Hillman and Adams, 1995; O’Brien, 2001; WBCSD, 2001). In developing nations, aspirations toward progress and status often translate into car ownership, even as the risks and costs of securing the energy to fuel these aspirations rise (Gakenheimer, 1999; Sperling and Clausen, 2002; WBCSD, 2001).

The factors described above have created not only compelling challenges for engineering, but also opportunities for social and business innovation. Smart mobility solution building is supported by new ways of thinking about sustainable urban transportation, as well as emerging tools and approaches for understanding, implementation, and commercialization. According to Susan Zielinski (2006) there are three frontiers of thinking and practice for Smart mobility, namely: complexity, accessibility and new business models (1).

To our view, in addition to Zielinski's frontiers of thinking there are at least three other fundamental aspects to be considered in order to create a framework for Smart mobility, namely: Matching Business and Technology;

Integrating Spatial Planning with Transportation Planning;

Promoting a cultural change.

5. Matching business and technology: the case of Hong Kong's Octopus System and OV-chipkaart in The Netherlands. A short history of success

The Octopus smart card is the most popular smart card in the Hong Kong Special Administrative Region (HKSAR), China. This case study traces the strategic moves of Octopus Cards Limited (OCL) in building an e-payment system and boosting its growth from limited deployment for transport payment in the initial stages to payments for various alternative forms of business transactions such as parking meters, supermarkets, restaurants, printing services in libraries, etc. This case is a classic example of technology penetration and diffusion, based on the alignment of business and information technology strategies. A strong interaction of business strategy and IT strategy can be seen as the firm evolved into a formidable player in the micro-payment business scenario. The case also analysis indicates that diffusion of a technology greatly depends on the dynamism in the technology and business environments. Finally it highlights the importance of business and technology strategies and their alignment.

The Mass Transit Railway (MTR), one of Hong Kong's railways, adopted a system to recirculate magnetic plastic cards as fare tickets when it started operations in 1979. Another of the territory's railway networks, the KowloonCanton Railway (KCR), adopted the same magnetic cards in 1984, and the stored value version was renamed Common Stored Value Ticket. In 1989, the Common Stored Value Ticket system was extended to Kowloon Motor Bus (KMB) buses providing a feeder service to MTR and KCR stations and to Citybus, and was also extended to a limited number of nontransport applications, such as payments at photo booths and for fast food vouchers (3).

The MTR Corporation eventually decided to adopt more advanced technologies, and in 1993 announced that it would move towards using contactless smartcards. To gain wider acceptance, it partnered with four other major transit companies in Hong Kong to create a joint-venture business to operate the Octopus system in 1994, then known as Creative Star Limited. The Octopus system was launched after three years of trials on 1 September 1997.

The Octopus card is a rechargeable contactless stored value smart card used to transfer electronic payments in online or offline systems in Hong Kong. Launched in September 1997 to collect fares for the territory's mass transit system, the Octopus card system was the first contactless smart card system in the world and has since grown into a widely used payment system for virtually all public transport in Hong Kong (4). The Octopus card is also used for payment at convenience stores, supermarkets, fast-food restaurants, on-street parking meters, car parks, and other point-of-sale applications such as service stations and vending machines. The Octopus card is recognised internationally, winning the Chairman's Award of the World Information Technology and Services Alliance's 2006 Global IT Excellence Award for being the world's leading complex automatic fare collection and contactless smartcard payment system, and for its innovative use of technologies. According to Octopus Cards Limited, operator of the Octopus card system, there are more than 20 million cards in circulation, nearly three times the population of Hong Kong. The cards are used by 95 percent of 
the population of Hong Kong aged 16 to 65, generating over 11 million daily transactions worth a total over HK\$100 million (US\$12.8 million) everyday.

The slogan of Octopus Card Limited and its products (the cards) is "Making Everyday Life Easier", which is part of the mission statement of the corporation.

The Octopus card uses radio frequency identification (RFID) technology so that users need only hold the card in close proximity of the reader. Physical contact is not required.

To communicate transaction information, transit stations have local area networks that connect the various components that deal with Octopus cards-turnstiles, add-value machines, analyzers and customer service terminals. These are connected to the MTRC's Kowloon bay headquarters through a frame relay wide area network. From here, all financial transactions are managed as different service providers relay their daily transaction information regarding purchases, usage statistics and added value.

Originally launched in September 1997 as a fare collection system for the Hong Kong's mass transit systems, the Octopus smart card has grown into a widely used electronic cash system for convenience stores, supermarkets, restaurants, parking garages and other point-ofsale applications. It has become one of the world's most successful e-cash systems, with over eleven million Octopus-cards circulating and over 80 service vendors (June 2010).

In 2000, the Hong Kong Monetary Authority granted a deposit-taking company license to the operator, removing previous restrictions that prohibited Octopus from generating more than 15 percent of its turnover from non-transit related functions, thus allowing the Octopus card to be widely adopted for non-transit-related sales transactions. On 29 June 2003, the Octopus card found another application when the Hong Kong Government started to replace all its 18,000 parking meters with a new Octopus card operated system. The replacement was completed on 21 November 2004.

In November 2003, Octopus Cards Ltd. secured a HK \$200 million contract to help provide contactless smartcard technology in The Netherlands' system, combining the fare collection system of its vive public transport companies -- rail operator Nederlandse Spoorwegen, bus and tramway operator ConneXXion, public transport companies of Rotterdam (RET) and Amsterdam (GVB) and the light train system in The Hague (HTM). The OV-chipkaart (from Dutch openbaar 'public' + vervoer 'transport' + chipkaart 'chip card') is a contactless smart card system which is in the process of being introduced and that eventually will operate on all public transport in the Netherlands, such as train, metro, tram and bus. It replaces both paper train tickets and the strippenkaart, which had hitherto been used for all other means of transport in the Netherlands. It allows the combination of card integration (the same card is used for multiple transport companies) and price differentiation (by company, time of day, day of the week, etc.), and reduces fare dodging. The OV-chipkaart is a cooperative initiative of five large publictransport operators: NS (railways), Connexxion (buses), RET (Rotterdam), GVB (Amsterdam), and HTM (The Hague). These five companies established the joint venture 'Trans Link Systems' (TLS) to implement the OV-chipkaart. The OV-chipkaart, the smart card for the Dutch public transportation system, is currently being rolled out on a big scale. The largest cities in The Netherlands (Amsterdam and Rotterdam) are exclusively making use of the OV-chipkaart for public transport. The smart card provides public transport with a national access control and settlement system that is implemented by all public transportation companies. It provides public transport with a national access control and settlement system that is implemented by all public transportation companies. As part of the smart card's continued development, Trans Link Systems (TLS) and the Open Ticketing Institute have asked Chess to design and industrialise the next OV-chipkaart generation. It must represent enhanced security whilst retaining the previous version's high performance. The handling speed between the OV-chipkaart and hardware determines throughput in public transportation. Based on Global Platform standards, Chess developed a Java Card and the embedded software for the card readers to comply with this requirement. Security and performance have been and are being audited by expert institutes.

Both cases (Hong Kong and The Netherlands) clearly show the benefits of matching technological innovation to business opportunities. However, attention should be paid to the 'transparency' of the system and particularly to the protection of users' privacy. Lately, the operator of the Octopus Hong Kong cashless payment system has come under fire after it reversed itself and admitted to selling the personal data of nearly two million customers to business partners, sparking public demands for better regulation of how personal information is handled. 
6. Integrating Spatial Planning with Transportation Planning: promoting a new urban mobility culture

One key condition for making Smart mobility a reality is to rebound the spatial planning task to transportation and traffic planning.

The challenge facing urban areas in the context of sustainable development is that of reconciling the economic development and accessibility of towns and cities with improving the quality of life and with environmental protection. In order to address these issues, which have many and varied implications, a cultural change is needed. Only through raising awareness of the problems and possible solutions, real progress can be made in cutting environmental, economic and human costs associated with traffic congestion. Changing mobility behaviour means developing strategies in collaboration with rather than for citizens. As urbanists we need to involve all parts of the community in finding the most appropriate solutions to suit local circumstances. We also need to create public awareness by raising initiatives targeted at the citizen on the damages that the current urban mobility trends generate on the local environment.

\section{Conclusions}

The increasingly complex living conditions of our contemporary cities and metropolises ask for a drastic shift from an "old" approach to mobility planning and management to a "new" one. Virtually all of the necessary preconditions are now in place for far-reaching, rapid, low cost improvements in the ways that people get around in our cites. The Smart mobility paradigm provides a consistent framework for new thinking and open collaborative group problem solving, bringing together several hundred of the leading thinkers and actors in the field, sharing information and considering together the full range of problems and eventual solution paths that constitute the global challenge of sustainable transport in cities.

\section{References}

(1) Zielinski, S., (2006) "Smart mobility: The Next Generation of Sustainable Urban Transportation", in The BRIDGE, Volume 36, Number 4 • Winter 2006; pp. 33-38.

(2) European Union, GREEN PAPER: Towards a new culture for urban mobility, Brussels, 25.9.2007

(3) "Our winning card". Tradelink Electronic Commerce Limited. January 2005..

(4) "Hong Kong Smart Card System". The World Bank Group. Archived from the original on March 4, 2007.

(5) Abbeele, G. van den, ( 1996) "Travel as Metaphor: from Montaigne to Rousseau". University of Minnesota, USA.
(6) Albertsen, N.; and Diken, B. (2000) What is the Social?. Available online at http://www.comp.lancs.ac.uk/sociology/soc033bd.htm 1

(7) Appleyard, D., Lynch, K., Meyer, J.R., (1963) “The View from the road”, MIT Press, Cambridge: MA, USA.

(8) Arida, A. (1998), "Quantum environments: urban design in the post-Cartesian paradigm”, in Planning Journal, Oxford Brookes University Joint Centre for Urban Design, Oxford , UK.

(9) Ascher, F., (2003) 'Movement at the heart of Modernity', in Architecture on the Move. Cities andMobilities, Paris: Institut pour la Ville en Mouvement, FR.

(10) Beckman, N. (1973), 'The Planner as a Bureaucrat', in: Faludi, A. (ed.) A Reader in Planning Theory. Pergamon Press, Oxford, UK, pp. 251-264.

(11) Calabrese, L.M., (2004) "Reweaving Uma. Urbanism, Mobility, Architecture", Delft University Press, Delft, NL

(12) Castells, M., (1996) "The information age: society and culture”, in Volume1, The rise of the network society, Blackwell Publishers Inc.,.Oxford, UK.

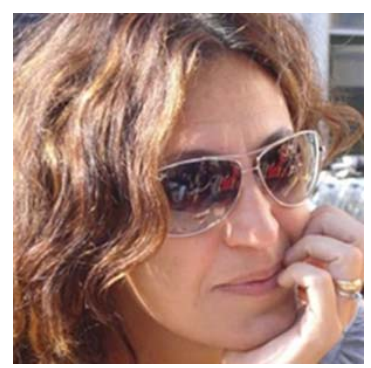

Luisa Maria Calabrese (Venezia, 1967)

Associate Professor, Department of Urban Design, Delft University of Technology; PhD in Urban Planning and Architecture; Professor of Urban Planning and Design at the Istituto Universitario di Architerrura ( IUAV, Italy); Degree in Architecture at the IUAV in Venice. She is internationally renowned for her studies and writings on sustainable mobility.

Director of the First International Architecture Biennale of Rotterdam "Mobility: a Room with a view" (2003-Curator Francine Houben-Mecanoo Architect). She has participated in numerous international research programs in partnership with several international universities. She is the Head of the Laboratory Vertical City Asia TUDelft and winner of awards in international competitions. 